\title{
Endometrial receptivity under hormone replacement therapy in oocyte-donation recipient patients: transcriptomic approach
}

\author{
D. Haouzi ${ }^{a_{1} b_{1} c}$, L. Bissonnette ${ }^{a_{1} b_{1} c_{1} d}$, H. Letur ${ }^{e}$, F. Entezami ${ }^{g}$, H. Perrochia ${ }^{\text {h }}$ H. Chahine ${ }^{g}$, F.

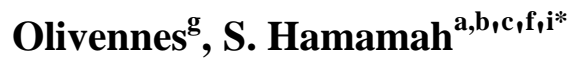

${ }^{\mathrm{a}} \mathrm{CHU}$ Montpellier, Institut de Medecine Regeneratrice et de Biotherapie, Hopital Saint-Eloi, Montpellier, 34295 France.

${ }^{\mathrm{b}}$ INSERM U1203 'Developpement embryonnaire precoce humain et pluripotence', Hopital Saint-Eloi, Montpellier, 34295 France.

${ }^{\mathrm{c}}$ Universite Montpellierl, UFR de Medecine.

${ }^{\mathrm{d} O V O}$ Fertility, 8000 Boulevard Decarie \#100, Montreal, Quebec, Canada H4P 2S4.

${ }^{\text {e }}$ Centre de fertilite de l'Institut Mutualiste Montsouris, Paris.

${ }^{\mathrm{f}}$ CHU Montpellier, ART/PGD Division, Departement de Biologie de la Reproduction, Hopital Arnaud de Villeneuve, Montpellier, F-34295 France.

${ }^{\mathrm{g}}$ Laboratoire d'Eylau-Unilabs, Clinique de la Muette, Paris, 75116 France.

${ }^{\text {h}} \mathrm{CHU}$ Montpellier, Hopital Gui de Chauliac, Service Anatomie cytologie pathologiques, Montpellier, F-34295 France.

*Corresponding author:

Mailing address:Pr. Samir Hamamah, ART/PGD Department, Arnaud de Villeneuve hospital, 34295 Montpellier, France. Phone: +33 (0)4 673364 04, Fax: +33 (0)4 673362 90, E-mail: shamamah@chu-montpellier.fr

\begin{abstract}
Purpose: Few studies have investigated the endometrial receptivity status of oocyte-donation (OD) recipient patients at the specific hormone replacement therapy (HRT)-cycle timing (5 to 6 days after progesterone administration) where embryos at blastocyst stage were mostly replaced. The aim of our study was to analyse, during the implantation window, (i) the global endometrial gene expression profile, and (ii) the endometrial receptivity exploration by the WinTest ${ }^{\circledR}$ in OD recipient patients under HRT compared to spontaneous cycle in patients awaiting for IVF.
\end{abstract}

Material and methods: This study included OD recipient patients without $(\mathrm{n}=7)$ or with (OD RIF, $\mathrm{n}=20)$ repeated implantation failures and 12 normal responder patients in spontaneous cycles used as control. Endometrial biopsies were performed during the peri-implantation phase. Samples were analysed using DNA microarrays and the endometrial gene expression profiles of HRTtreated OD recipient patients and of patients in spontaneous cycles were compared. Then, specific biomarkers of endometrial receptivity were assessed in the two groups of HRT-treated OD patients in comparison to control patients

Results: The global gene expression profile of peri-implantation endometrial samples from HRT-treated OD recipients and from patients in spontaneous cycles was different with significant alterations in the oestrogen receptor signalling $[G T F 2 H 2 B, P O L R 2 B, P O L R 2 E]$, VEGF family ligand-receptor interactions [VEGFRI, VEGFB] and integrin signalling [ITGAL, PAK7, ILK]. Using specific biomarkers of human endometrial receptivity, we found that endometrium was non-receptive $(29 \%$ and $43 \%$ in OD and RIF OD patients, respectively) or partially receptive (71 and $43 \%$ in OD and RIF OD patients, respectively), at $\mathrm{Pg}+5 /+6$, in majority of HRT-treated patients. In OD RIF patients, a delay of the implantation window was observed. However, by targeting personalized embryos transfer by identifying for each patient the HRTcycle day where endometrium is receptive, with respect of the synchronization of embryo-endometrium dialogue, high pregnancy rate per frozen-thawed embryo replacement $(50 \%)$ was obtained in OD RIF patients.

Conclusion: This study underlines the need to take into account the individual patient's response to HRT cycles and to move to a patient-tailored care management.

Keywords: Endometrial receptivity, HRT, oocyte donation recipients, gene expression, implantation window, Win-Test. 


\section{Introduction}

Hormonal preparation of the endometrium is a common practice in assisted reproductive technologies (ART) and is considered crucial for recipients of oocyte donation, for infertile women undergoing fresh or frozen embryo replacement and for patients who had several unsuccessful in vitro fertilization (IVF) cycles due to implantation failure. Such hormonal treatments frequently include the sequential administration of oestrogen and progesterone to prepare the uterus to receive the embryo by mimicking the hormonal microenvironment of the endometrium during the implantation window. Oestrogen induces the proliferation of endometrial cells in the basal layer during the first phase of the menstrual cycle and prepares the endometrium to respond to progesterone during the second phase, a necessary step to induce the morphological, biochemical and molecular changes required for endometrium receptivity during the implantation window. Adequate concentrations of both oestrogen and progesterone are therefore essential for optimal endometrial maturation in order to increase the implantation rate and pregnancy chances. Many regimens have been described with different doses, routes and duration of administration of oestrogen and progesterone (Kolibianakis et al., 2008; Glujovsky et al., 2010; van der Linden et al., 2011). However, to date, there is insufficient evidence to advice a specific regimen rather than another.
In addition, controversial results have been reported concerning the beneficial effect of luteal phase oestrogen supplementation on implantation and pregnancy rates (Smitz et al., 1993; Lewin et al., 1994; Farhi et al., 2000; Gleicher et al., 2000; Jung and Roh, 2000; Gorkemli et al., 2004; Fatemi et al., 2006; Lukaszuk et al., 2005; Ceyhan et al., 2008; Engmann et al., 2008; Serna et al., 2008). In most reported papers, the strategy for embryos replacement under HRT, is the following one: replacement of day- $2 / 3$ embryos and blastocysts stages on the third and fifth day of progesterone administration respectively (Nawroth and Ludwig, 2005; Shapiro et al., 2014). However, what we really know about the endometrial receptivity status at these specific HRT-cycle timing? Using their biomarkers of endometrial receptivity (ERA), a recent study reported a non-receptive endometrial profile under HRT after five days of progesterone treatment in 17 patients undergoing oocyte donation (OD) with implantation failure(s) (RIFs) (RuizAlonso et al., 2014).

Our group previously identified specific biomarkers of human endometrial receptivity (Haouzi et al., 2009; Haouzi et al., 2012). As extensively discussed in Haouzi et al. (2012), the number of patients and of endometrial samples used to select a set of genes to develop the two endometrial receptivity tests (Win-Test ${ }^{\circledR}$ and ERA test, respectively) were 
not comparable, leading necessarily to the identification of distinct endometrial receptivity biomarkers. The aim of our study was to analyse, during the implantation window, (i) the global endometrial gene expression profile, and (ii) the endometrial receptivity exploration by the $\mathrm{Win}^{-\mathrm{Test}^{\circledR}}{ }^{\circledR}$ in candidates for oocyte donation recipients under HRT compared to control group.

\section{1-Materials and methods}

The study was approved by the Ethical Committee of the Institut de Médecine Régénératrice et de Biothérapie.

\section{Patients' characteristics and endometrial biopsies}

Patients were recruited after written informed consent.

\section{Patients receiving $H R T$ regimen:}

Seven patients without ovarian function and referred for OD (age $34 \pm 4.8$ years) were recruited for this study from the Fertility Centre of the Institut Mutualiste Montsouris of Paris. Lack of ovarian function in these patients with amenorrhoea of 6 months or more was diagnosed according to their serum follicle stimulating hormone (FSH >30 IU/l), luteinizing hormone ( $\mathrm{LH}>25 \mathrm{IU} / \mathrm{ml})$ and oestradiol level $(\mathrm{E} 2<5 \mu \mathrm{g} / \mathrm{ml})$. In these patients, menstrual bleeding can be induced by the sequential use of estrogen plus progestogen. The HRT consisted of a daily oral dose of $4 \mathrm{mg}$ oestradiol (Provames $2 \mathrm{mg}$, Sanofi-Aventis France) between day 1 and day 6 after the menses for one month supplemented with $400 \mathrm{mg}$ per day of vaginal progesterone suppositories (Utrogestan 200 mg, Besins International France) from day 15 after the beginning of HRT for fourteen days. Menstrual bleeding occurred one to six days after stopping HRT of one treatment cycle. Endometrial biopsies were performed on day twenty of HRT (sixth day after the beginning of progesterone $(\mathrm{Pg})$ administration, corresponding to five days of progesterone treatment; recipient $\mathrm{Pg}+5$ samples). Doppler ultrasonography, serum progesterone and oestradiol measurement were performed at day 14 and day 20 of HRT (Supplementary Table 1). Serum progesterone and oestradiol were measured by using an automated Architect I2000 instrument (Abbott Diagnostic). Intra-assays and inter-assay coefficients of variation $(\mathrm{CV})$ were $<2.7 \%$ and $<9.1 \%$ for progesterone and $<5 \%$ and $<10 \%$ for oestradiol.

Twenty OD patients with RIFs (4 \pm 0.5 ) (age $37.2 \pm 1.5$ years) were also included. Clinical characteristics and outcomes of RIF patients were reported in the Table 1. These patients were under HRT regimen for endometrial receptivity detection using the Win-Test ${ }^{\circledR}$ and thawed-cryopreserved embryo replacement according to the Win-Test result. HRT regimen involved either a daily oral dose of 6 
mg oestradiol (Provames $2 \mathrm{mg} \mathrm{x} 3$ / day) or a of progesterone (Utrogestan $200 \mathrm{mg}$ ) from progressive dose (2mg/day during 3 days, 4 days 15-28. In this group, endometrial biopsy $\mathrm{mg} /$ day during 5 days and $6 \mathrm{mg} /$ day) on day was performed between $\mathrm{Pg}+5$ to $\mathrm{Pg}+8$.

1-28 combined with 400 or $600 \mathrm{mg}$ per day

\begin{tabular}{ccccc} 
Patient's number & Age (years) & Infertility causes & $\begin{array}{c}\text { Number of } \\
\text { previous failed } \\
\text { CoS cycles }\end{array}$ & $\begin{array}{c}\text { Number of non-implanted } \\
\text { replaced embryos with ovum } \\
\text { donation }\end{array}$ \\
\hline P1 & 35 & Idiopathic & 1 & 2 \\
P2 & 41.1 & Idiopathic & 2 & 5 \\
P3 & 49.75 & advanced maternal age, ovarian failure & 0 & 15 \\
P4 & 37.54 & azoospermia and idiopathic & 8 & 8 \\
P5 & 44.5 & Idiopathic & 8 & 4 \\
P6 & 34.75 & tubal infertility & 3 & 9 \\
P7 & 27.75 & endometriosis and PCOS & 2 & 5 \\
P8 & 24.9 & endometriosis and spanomenorrhoea & 2 & 9 \\
P9 & 43 & Idiopathic & 8 & 7 \\
P10 & 40.42 & Endometriosis & 3 & 5 \\
P11 & 38.33 & PCOS and OATS & 3 & 6 \\
P12 & 34.5 & OATS & 4 & 10 \\
P13 & 42 & Idiopathic & 5 & 7 \\
P14 & 36 & excretory azoospermia & 7 & 6 \\
P15 & 32.58 & tubal and cervical infertility & 6 & 11 \\
P16 & 31 & male infertility & 3 & 4 \\
P17 & 34.58 & male infertility & 2 & 10 \\
P18 & 35.66 & Dysovulation & 6 & 7 \\
P19 & 31.66 & Idiopathic & 5 & 3 \\
P20 & 49.6 & idiopathic, advanced maternal age & 3 & 5 \\
\hline
\end{tabular}

Table 1: Clinical characteristics and outcomes of RIF patients.

PCOS, polycystic ovary syndrome; OATS, oligoasthenoteratozoospermia; COS, controlled ovarian stimulation

Patients in spontaneous cycle used as

control:

Twelve patients (age $31.5 \pm 3$ years), with $2(\mathrm{LH}+2)$ and day $7(\mathrm{LH}+7)$ after the $\mathrm{LH}$ regular menstrual cycle (28-32 days), surge during the spontaneous cycle. They did followed for intracytoplasmic sperm injection not receive any treatment for at least three (ICSI) due to male infertility, were included. months before the endometrial biopsy and Endometrial biopsies were carried out at day were included as control group. 


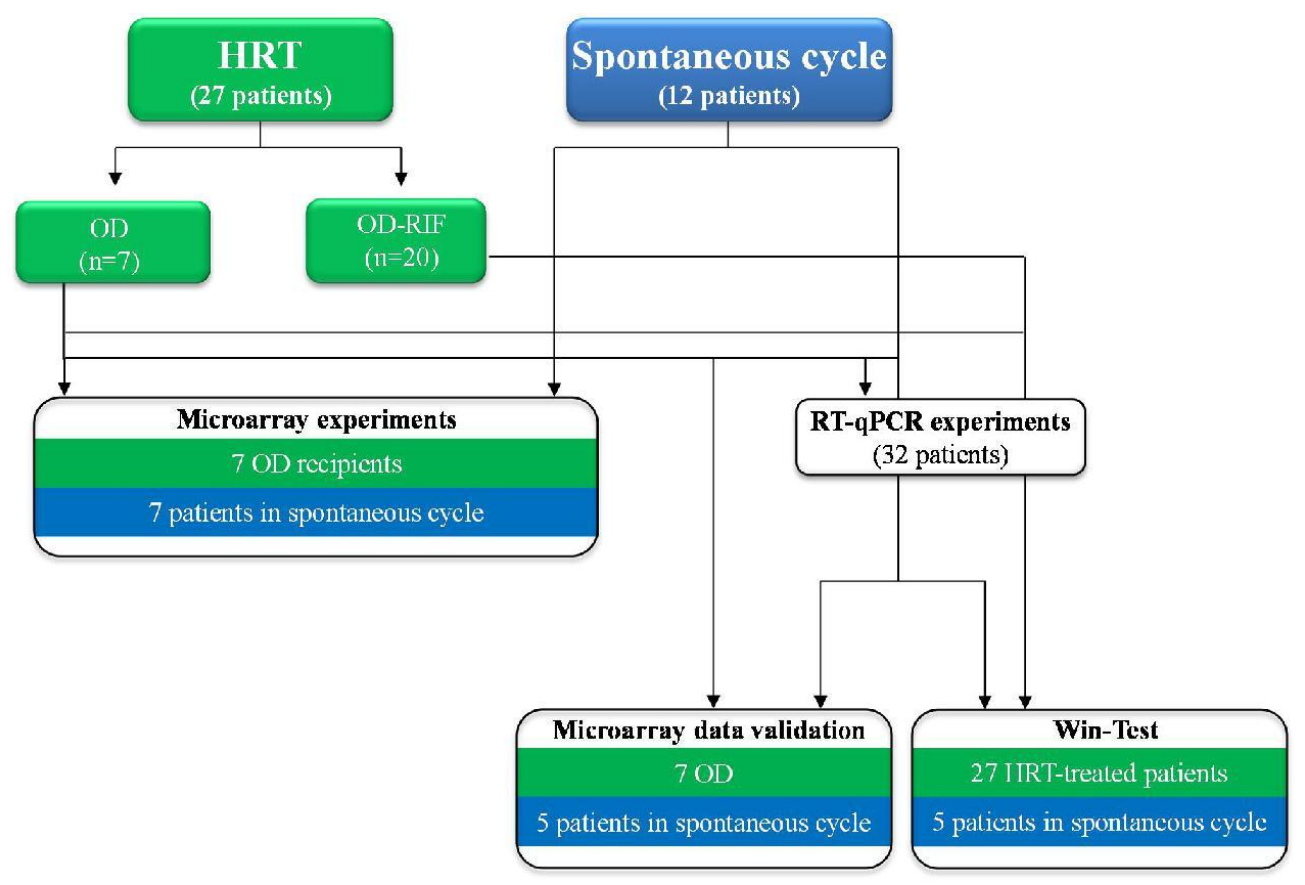

Figure 1: Study design

\section{Endometrial biopsies:}

After washing with phosphate buffered saline, biopsies were frozen individually at $80^{\circ} \mathrm{C}$ prior to total RNA extraction with the RNeasy Mini Kit (Qiagen, Valencia, CA, USA) (see Fig. 1 for the study design).

For microarray experiments, seven LH+7 and seven recipient $\mathrm{Pg}+5$ endometrial samples were used. Five $\mathrm{LH}+2$ samples, five $\mathrm{LH}+7$ samples, seven recipient $\mathrm{Pg}+5$ samples and twenty RIF $\mathrm{Pg}+5 /+8$ samples (thus, in total 27 samples from HRT-treated patients) were used for RT-qPCR experiments to validate some microarray data and/or to assess endometrial receptivity using the Win-Test described below.

\section{Microarray hybridization}

Affymetrix microarrays were processed at the Microarray Core Facility of the Institute for Regenerative Medicine and Biotherapy, CHRU-INSERM-UM Montpellier (http://irmb.chu-montpellier.fr). Total RNA (100ng) was used to prepare twice-amplified and labelled cRNA samples for hybridization with HG-U133 plus 2.0 arrays (Affymetrix $^{\mathrm{TM}}$, United Kingdom, UK) as described in Haouzi et al., 2009. Each endometrial sample was processed individually on a separate DNA microarray chip.

\section{Data processing and microarray data}

\section{analysis}

Scanned GeneChip images were processed using the Affymetrix GCOS 1.4 software to obtain the intensity value signal and the absent/present detection call for each probe 
set using the default analysis settings and global scaling as first normalization method. Probe intensities were derived using the MAS5.0 algorithm.

To compare endometrial gene expression profiles between HRT-treated recipients and spontaneous cycle patients, first an unsupervised hierarchical clustering of the $\mathrm{LH}+7 \quad(\mathrm{n}=7)$ and recipient $\mathrm{Pg}+5 \quad(\mathrm{n}=7)$ samples was performed using the CLUSTER and TREEVIEW software packages (de Hoon et al., 2004). For this, a probe set selection using the detection call (present in at least seven endometrial samples) and a coefficient of variation $(\mathrm{CV}) \geq 40 \%$ between samples was carried out. Then, the significant analysis of microarrays (SAM, Stanford University, USA, Thusher et al., 2001) was used to identify genes the expression of which varied significantly between $\mathrm{LH}+7$ and recipient $\mathrm{Pg}+5$ endometrial samples. The list of differentially expressed genes (Fold change, FC $>2$; False discovery rate, FDR $<5 \%$ ) was submitted to Ingenuity (http://www.ingenuity.com) to identify the signalling pathways altered by HRT in recipient patients.

\section{The Win-Test ${ }^{\circledR}$ : a genomic exploration for the implantation window determination}

Our transcriptomic data issues from Haouzi et al., (2009, 2012, 2014) have provide evidence for the identification of 13 specific biomarkers of human endometrial receptivity, that are overexpressed during the implantation window. Then, we developed a test based on the mRNA expression levels of these 13 biomarkers by RT-qPCR that we called the 'Win-Test ${ }^{\circledR}$, (Window Implantation Test) (Patent EP10305561.2; PCT/EP2011/058757). The 'Win-Test ${ }^{\circledR}$, allows to classify endometrial samples obtained during the implantation window as 'receptive' (R), partially receptive (PR) or 'non-receptive' (NR). Partially receptive profile is considered when the expression levels of the 13 biomarkers were situated around $50 \%$.

\section{Replacement strategy according to the Win- Test ${ }^{\circledR}$ and pregnancy outcome}

The strategy of the personalized embryo transfer consists to perform embryos replacement at blastocyst stage when endometrium is receptive or day-2/3 embryos replacement when endometrium is going to acquire the receptive phenotype (partially receptive).

\section{Quantitative RT-PCR analyses}

For the Win-Test $^{\circledR}, \quad 0.5 \mu \mathrm{g}$ RNA from recipient $\mathrm{Pg}+5 \quad(\mathrm{n}=7)$ and $\mathrm{RIF} \mathrm{Pg}+5 /+8$ endometrial samples $(\mathrm{n}=20)$ (both from patients receiving HRT) or from $\mathrm{LH}+7(\mathrm{n}=5)$ (receptive endometrium; positive control) and $\mathrm{LH}+2$ samples $\quad(\mathrm{n}=5) \quad$ (pre-receptive endometrium, negative control) was used for 
reverse transcription-quantitative polymerase chain reaction (RT-qPCR) analysis according to the manufacturer's recommendations (Applied Biosystems, Villebon sur Yvette, France). For validation of some genes identified as differentially expressed in the recipient $\mathrm{Pg}+5$ endometrial samples according to the functional annotation of the microarray data, five recipient $\mathrm{Pg}+5$ and five LH+7 endometrial samples were also used. For qPCR, $2 \mu 1$ of first strand DNA (diluted 1:5) were added to a $10 \mu 1$ reaction mixture containing $0.25 \mu \mathrm{M}$ of each primer and $5 \mu \mathrm{l}$ of 2X LightCycler 480 SYBR Green I Master mix (Roche, Mannheim, Germany). DNA was amplified for 45 cycles with annealing temperature set at $63^{\circ} \mathrm{C}$ using the Light Cycler 480 detection system (Roche). Sample expression values were normalized to $P G K I$ (Phosphoglycerate kinase 1) expression using the following formula: $\mathrm{E}_{\text {tested primer }} \Delta \mathrm{Ct} / \mathrm{E}_{P G K I}$ $\Delta \mathrm{Ct}\left(\mathrm{E}=10^{-1 / \text { slope }}\right), \Delta \mathrm{Ct}=\mathrm{Ct}$ control $-\mathrm{Ct}$ unknown, where $\mathrm{E}$ corresponds to the efficiency of the PCR reaction. The E value was obtained by a standard curve that varies in function of the primers used. One receptive endometrium sample from a patient in spontaneous cycle $(\mathrm{LH}+7)$ was used as control. Each sample was analysed in duplicate and multiple water blanks were included.

\section{Statistical analyses}

Statistical analyses of the clinical and RTqPCR data were performed using the
GraphPad InStat 3 software. For clinical data, differences between groups were considered significant when the Student's $t$ test gave a Pvalue $<0.05$. For RT-qPCR data, a repartition difference between sample groups was considered significant when the KruskalWallis test (Dunn's multiple comparison test) gave a $\mathrm{P}$-value $<0.05$.

\section{2-Results}

\section{Global transcriptomic profiles of $O D$} recipient patients during periimplantation endometrial period under HRT treatment We selected 13924 genes $(\mathrm{CV} \geq 40 \%$ and a 'present' detection call in at least seven samples) and then compared their expression in the 14 endometrial samples (seven recipient $\mathrm{Pg}+5$ and seven $\mathrm{LH}+7$ control group, respectively) by performing unsupervised hierarchical clustering (Fig. 2A). A first branch separated most recipient Pg+5 samples (6 out of $7 ; 86 \%$ ) from the LH+7 samples, suggesting that the endometrial profile at $\mathrm{Pg}+5$ in HRT-treated OD recipients is different from the profile of receptive endometrial samples from patients of control group. SAM analysis of the two groups confirmed these findings as 2291 genes were differentially expressed between $\mathrm{LH}+7$ and recipient $\mathrm{Pg}+5$ samples (Fig. 2B). The Doppler parameters were good in all patients and no differences between HRTtreated oocyte-donation recipients were reported. 
A

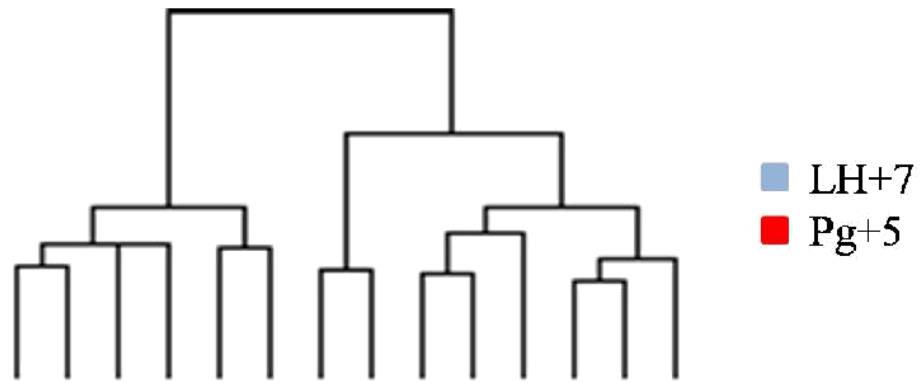

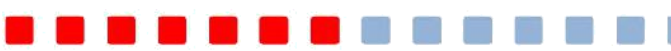

\section{B}

\begin{tabular}{cccc} 
& \multicolumn{3}{c}{ Number of genes } \\
\cline { 2 - 4 } & $\mathrm{Up}$ & Down & Total \\
\hline $\mathrm{LH}+7$ vs $. \mathrm{Pg}+5$ & 1814 & 477 & 2291 \\
\hline
\end{tabular}

Figure 2: (A) Unsupervised classification with hierarchical clustering of 14 endometrium samples from patients in spontaneous cycles $(\mathrm{LH}+7, \mathrm{n}=7)$ and recipient patients receiving HRT $(\mathrm{Pg}+5, \mathrm{n}=7)$. (B) Number of genes that are differentially expressed during the periimplantation period in the $\mathrm{LH}+7$ and $\mathrm{Pg}+5$ samples shown in A.

\section{Typical peri-implantation endometrial gene}

\section{expression profile in HRT-treated OD}

recipients

Analysis of the specific profile of recipient patients at $\mathrm{Pg}+5$ samples using the Ingenuity system identified five canonical signalling pathways that were significantly affected by HRT during the implantation window: 'oestrogen receptor signalling', 'hereditary breast cancer signalling', 'VEGF family ligand-receptor interactions', 'tumoricidal function of hepatic natural killer cells' and 'integrin signalling' (Table 2 and Fig. 3). The differential expression of some of these genes in recipient $\mathrm{Pg}+5$ and $\mathrm{LH}+7$ endometrial samples was validated by RTqPCR analysis (Supplementary Fig. 1). 


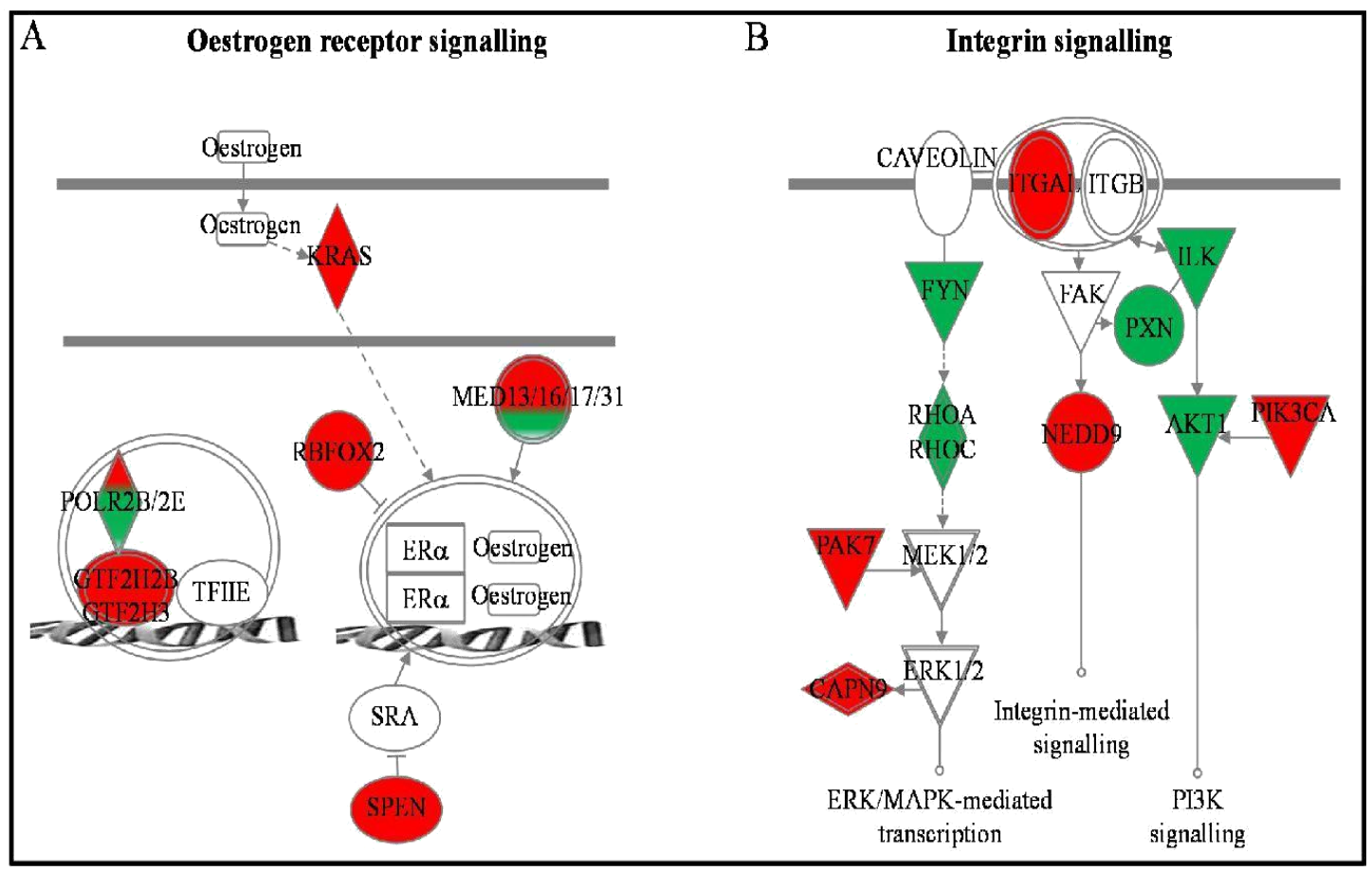

Figure 3: Alteration of oestrogen receptor (ER) (A) and integrin (B) signalling during the implantation window in the endometrium of recipients patients receiving HRT compared to the endometrium of patients in spontaneous cycles (control). In this network, edge types are indicatives: a plain line indicates direct interactions, a dashed line indicates indirect interactions, a line without arrowhead indicates binding only, a line finishing with a vertical line indicates inhibition, a line with an arrowhead indicates «acts on». Green, genes downregulated ; Red, genes up-regulated relative to control. 


\begin{tabular}{|c|c|c|c|c|c|}
\hline Gene Name & Fold change & FDR & WEE1 & 2 & 0.003 \\
\hline \multicolumn{3}{|c|}{ Oestrogen receptor } & $P I K 3 C A$ & 2.2 & 0.01 \\
\hline \multicolumn{3}{|l|}{ signalling: } & \multicolumn{3}{|c|}{ VEGF family ligand-receptor interactiol } \\
\hline$G T F 2 H 2 B$ & 2.3 & 0.03 & & & \\
\hline$G T F 2 H 3$ & 2.2 & 0.002 & VEGFR1 & 2.9 & 0.008 \\
\hline$K R A S$ & 2.1 & 0.003 & $V E G F B$ & 2.3 & 0.004 \\
\hline$R R A S$ & 3 & 0 & PLA2G10 & 2.2 & 0.04 \\
\hline MED13 & 2 & 0.002 & $P L A 2 G 4 F$ & 2.2 & 0.03 \\
\hline MED16 & 2 & 0.003 & \multicolumn{3}{|c|}{ Tumoricidal function of hepatic natural } \\
\hline$M E D 17$ & 2.3 & 0.03 & \multicolumn{3}{|l|}{ killer: } \\
\hline$M E D 31$ & 2.2 & 0.02 & & & \\
\hline$P O L R 2 B$ & 2.1 & 0.0004 & $S R G N$ & 2.3 & 0.01 \\
\hline POLR2E & -2.1 & 0 & $A P A F 1$ & 2.2 & 0 \\
\hline TAF15 & 2.3 & 0.003 & CASP6 & 2.1 & 0.003 \\
\hline SPEN & 2 & 0.03 & $I T G A L$ & 2.4 & 0.01 \\
\hline RBM9 & 2.2 & 0.04 & \multicolumn{3}{|c|}{ Integrin signalling: } \\
\hline$T H R A P 1$ & 2.9 & 0.02 & CAPN9 & 2.3 & 0.04 \\
\hline HSDL2 & 2.1 & 0 & $I T G A L$ & 2.4 & 0.01 \\
\hline RDH5 & 2.1 & 0.03 & $F Y N$ & 2.5 & 0.01 \\
\hline DHRS3 & 2.1 & 0.04 & $I L K$ & 2.4 & 0 \\
\hline$D H R S X$ & 2.3 & 0.03 & NEDD9 & 2.9 & 0.02 \\
\hline \multicolumn{3}{|c|}{ Hereditary breast cancer signalling: } & $P A K 7$ & 5.8 & 0.04 \\
\hline$A K T 1$ & 2.6 & 0.003 & $P P P 1 C B$ & 2.2 & 0.015 \\
\hline CDK6 & 2.1 & 0.01 & $P X N$ & 2.1 & 0 \\
\hline$G A D D 45 B$ & 2.5 & 0.04 & RHOA & 2 & 0.003 \\
\hline$K R A S$ & 2.1 & 0.003 & RHOC & 2.1 & 0 \\
\hline$R C F 5$ & 2.2 & 0 & PIK3CA & 2.2 & 0.01 \\
\hline$S M A R C A 2$ & 3.7 & 0.004 & $R R A S$ & 3 & 0 \\
\hline
\end{tabular}

Table 2: Genes associated with canonical signalling pathways that were specifically deregulated in HRT-treated oocyte-donation recipients compared to patients in spontaneous cycle. 
Major differences in the expression of genes encoding growth factors, growth factor receptors, adhesion and extracellular matrix molecules in peri-receptive endometrial samples from HRT-treated OD recipients

We then focused on the expression of genes encoding extracellular matrix and adhesion molecules, growth factors and growth factor receptors that play a central role in embryo implantation by controlling the local microenvironment and allowing the endometrium to become receptive.

Growth factors, such as $I L 7 R(\mathrm{x} 2.5, \mathrm{FDR}=0.042)$, FGFR2 (x2.4, FDR=0.005) and JAG1 (x2.5, $\mathrm{FDR}=0.01$ ), were over-expressed in peri-receptive recipient at $\mathrm{Pg}+5$ samples, while $O G F R$ (x-2.1, $\mathrm{FDR}=0.005), \quad V E G F B(\mathrm{x}-2.3, \mathrm{FDR}=0.005)$ and VEGFR1 (x-2.9, FDR=0.008) were downregulated. Among chemokines, CXCL11 (x2.9, $\mathrm{FDR}=0.02)$ and $C C R 1(\mathrm{x} 2.7, \mathrm{FDR}=0.04)$ were upregulated in recipient $\mathrm{Pg}+5$ samples.

Several integrins $[I T G B 1 B P 1(\mathrm{x}-2, \mathrm{FDR}=0.003)$, ITGAL $\quad(\mathrm{x} 2.4, \quad \mathrm{FDR}=0.01), \quad$ ITFG1 $\quad(\mathrm{x} 2.4$, FDR=0.04) $], \quad$ collagens $\quad[C O L 4 A 3 B P \quad(x 3.9, \quad \mathrm{Pg}+7 /+8$, majority of evaluated RIF patients were $\mathrm{FDR}=0.03), \quad$ COLAA1 $\quad(\mathrm{x} 2.8, \quad \mathrm{FDR}=0.04) \quad$ and 'receptive' $(77 \%)$.
COL1A2 (x2.2, FDR=0.02)], glycoproteins $[C D 44$ $(\mathrm{x}-2.1, \quad \mathrm{FDR}=0.01), \quad C D 248 \quad(\mathrm{x}-2.2, \quad \mathrm{FDR}=0.03)$ and $C D 24(\mathrm{x}-2.3, \mathrm{FDR}=0.01)$ as well as LAMA5 (2, FDR=0.04), ADAMDEC1 (x2.9, FDR=0.04), TMEM212 (x2.6, FDR=0.04), TMEM77 (x2.5, FDR=0.03), TMEM27 (x2.1, FDR=0.02), TMEM161A (x-2.1, FDR=0.003), TMEM204 (x2.1, FDR=0.004) and EZR (x-2.4, FDR=0.01)] were significantly deregulated in recipients at $\mathrm{Pg}+5$ compared to control group.

\section{Endometrial receptivity under HRT in OD} recipients and in OD RIF patients: the WinTest $^{\circledR}$ data

Only one biomarker (KRT80) among the 13 biomarkers showed a similar expression profile in OD recipient samples at $\mathrm{Pg}+5$ and control group (Fig. 4). Analysis of the Win-Test ${ }^{\circledR}$ results in each patient revealed that $71 \%$ of OD recipient samples at $\mathrm{Pg}+5$ were only 'partially receptive' and $29 \%$ were non-receptive (Table 3). In OD RIF patients, 7 have been evaluated at $\mathrm{Pg}+5 /+6$ and 10 at $\mathrm{Pg}+7 /+8$. At $\mathrm{Pg}+5 /+6$, only $14 \%$ of patients were 'receptive', $43 \%$ and $43 \%$ were 'partially' and 'non-receptive' respectively. At 

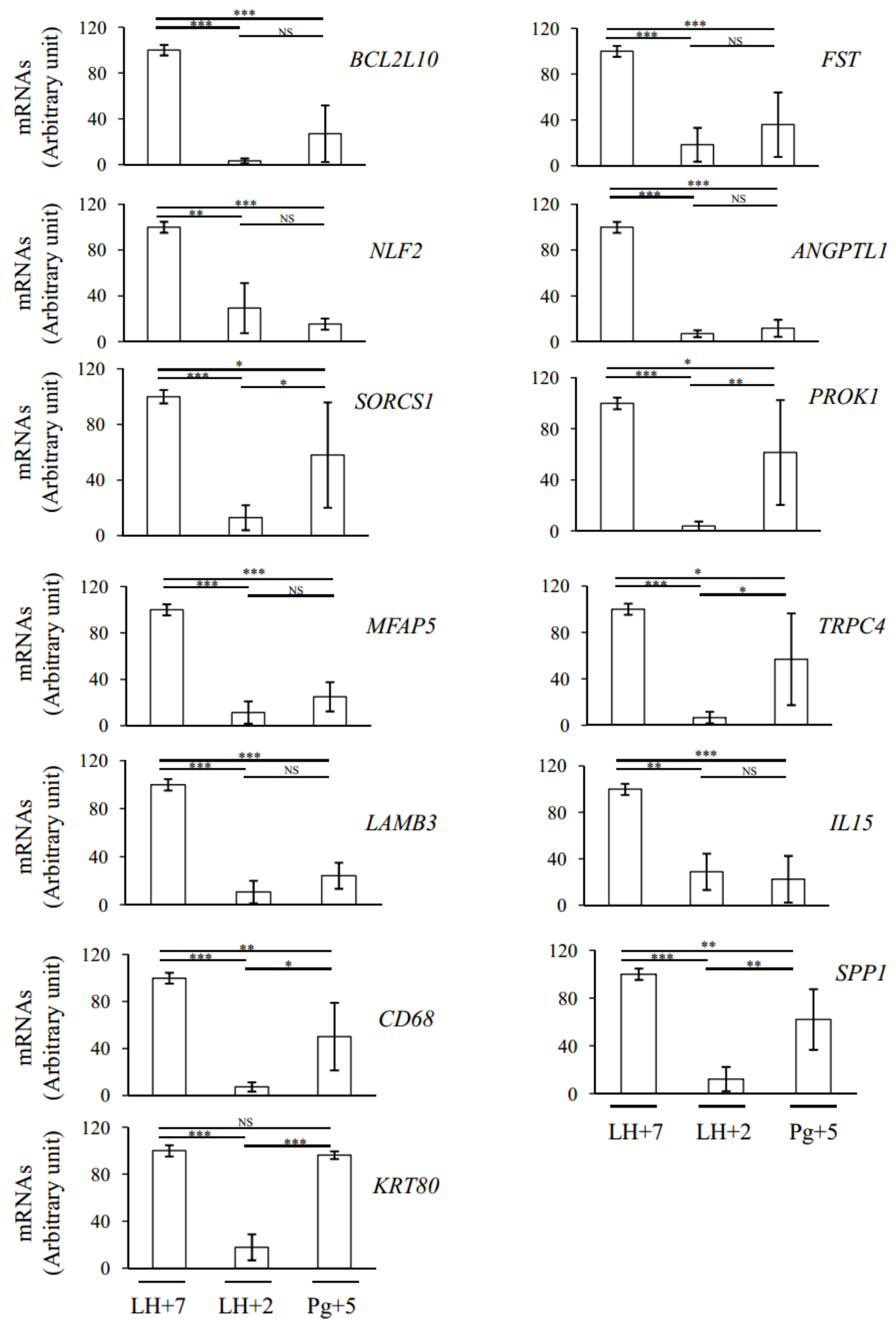

Figure 4: Analysis of the expression of endometrial receptivity biomarkers by RTqPCR in Pg+5 endometrial samples from recipient patients receiving HRT. Data are the mean \pm SEM.

$* * *, p<0.001 ; * *, p<0.01 ; *, p<0.05$ and NS, non-significant compared to the expression values in $\mathrm{LH}+2$ (pre-receptive phase) and LH+7(receptive phase in spontaneous cycles) endometrial biopsies. 


\begin{tabular}{ccccc}
\hline Patient's number & $\begin{array}{c}\text { Win-Test's result } \\
\text { (biopsy at Pg+5) }\end{array}$ & $\begin{array}{c}\text { Biochemical } \\
\text { pregnancy }\end{array}$ & $\begin{array}{c}\text { Clinical } \\
\text { pregnancy }\end{array}$ & Birth \\
\hline P1 & PR & + & + & No (clinical abortion) \\
P2 & PR & + & + & Yes \\
P3 & PR & + & + & Yes \\
P4 & PR & - & & \\
P5 & PR & - & & \\
P6 & NR & - & & \\
P7 & NR & - & & \\
\hline
\end{tabular}

Table 3: Results of the Win-Test ${ }^{\circledR}$ in each HRT-treated oocyte-donation recipient. PR, partially receptive; NR, non-receptive.

On the other hand, after the first endometrial receptivity evaluation, only $50 \%$ of OD RIF patients were receptive, 35 and $15 \%$ were 'partially' and 'non-receptive' respectively, between $\mathrm{Pg}+5$ to $\mathrm{Pg}+8$. All 'non-receptive' patients after the first Win-Test ${ }^{\circledR}$ were diagnosed as 'receptive' after the second evaluation. Among 'receptive' patients, 7, 43,
43, and $7 \%$ were specifically at $\mathrm{Pg}+6, \mathrm{Pg}+7$, $\mathrm{Pg}+8$ and $\mathrm{Pg}+9$ respectively (Fig. 5). In OD RIF patients, embryo transfer has been performed according both the Win-Test ${ }^{\circledR}$ result and the cryopreserved embryonic developmental stage (Table 4). In these conditions, the clinical pregnancy rate was $50 \%$ per frozen -thawed embryo replacement.

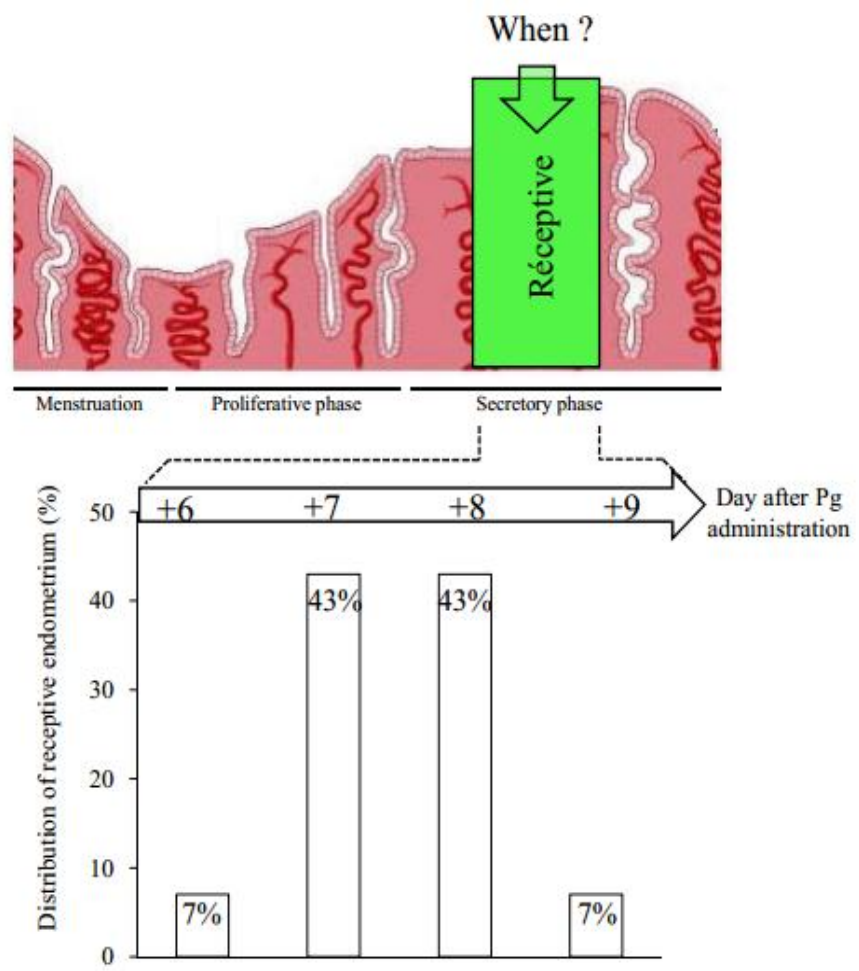

Figure 5: Distribution of receptive samples diagnosed by the Win-Test ${ }^{\circledR}$ results according to the HRT- cycle timing. Pg, progesterone. 


\begin{tabular}{|c|c|c|c|c|c|c|c|c|}
\hline Patient's number & $\begin{array}{l}\text { Cycle day of the } \\
\text { first Win-Test }\end{array}$ & $\begin{array}{l}\text { Result of the } \\
\text { first Win-Test }\end{array}$ & $\begin{array}{l}\text { Cycle day } \\
\text { of the } \\
\text { second Win- }\end{array}$ & $\begin{array}{l}\text { Result of } \\
\text { the second } \\
\text { Win Test }\end{array}$ & $\begin{array}{c}\text { Cycle day of embryo } \\
\text { replacement }\end{array}$ & $\begin{array}{c}\text { Transfered embryonic } \\
\text { developement stage }\end{array}$ & $\begin{array}{l}\text { Biochemical } \\
\text { pregnancy }\end{array}$ & $\begin{array}{r}\text { Clinical } \\
\text { pregnancy }\end{array}$ \\
\hline P1 & $\mathrm{Pg}+7$ & $\mathrm{R}$ & & & $\mathrm{Pg}+5$ & Day 3 embryo & + & + \\
\hline P2 & $\mathrm{Pg}+6.5$ & $\mathrm{R}$ & & & $\mathrm{Pg}+7.5$ & Blastocyst & + & + \\
\hline P3 & $\mathrm{Pg}+6.5$ & NR & $\mathrm{Pg}+8$ & $\mathrm{R}$ & $\mathrm{Pg}+8$ & Blastocyst & + & + \\
\hline $\mathrm{P} 4$ & $\mathrm{Pg}+6.5$ & NR & $\mathrm{Pg}+8$ & $\mathrm{R}$ & $\mathrm{Pg}+8$ & Blastocyst & - & \\
\hline P5 & $\mathrm{Pg}+8$ & PR & & & $\mathrm{Pg}+6$ & Day 2 embryo & + & + \\
\hline P6 & $\mathrm{Pg}+8$ & $\mathrm{R}$ & & & $\mathrm{Pg}+8$ & Blastocyst & - & \\
\hline P7 & $\mathrm{Pg}+7$ & PR & $\mathrm{Pg}+9$ & $\mathrm{R}$ & $\mathrm{Pg}+7$ & Day 3 embryo & + & + \\
\hline P8 & $\mathrm{Pg}+7$ & $\mathrm{R}$ & & & $\mathrm{Pg}+7$ & Blastocyst & - & \\
\hline P9 & $\mathrm{Pg}+7.5$ & $\mathrm{R}$ & & & Pg7.5 & Blastocyst & - & \\
\hline $\mathrm{P} 10$ & $\mathrm{Pg}+8$ & PR & & & $\operatorname{Pg} 7.5$ & Day 3 embryo & - & \\
\hline P11 & $\mathrm{Pg}+7$ & PR & & & $\mathrm{Pg}+7$ & Day 3 embryo & + & + \\
\hline $\mathrm{P} 12$ & $\mathrm{Pg}+7$ & $\mathrm{R}$ & & & $\mathrm{Pg}+7$ & Blastocyst & - & \\
\hline P13 & $\mathrm{Pg}+8$ & $\mathrm{R}$ & & & $\mathrm{Pg}+8$ & Blastocyst & - & \\
\hline P14 & $\mathrm{Pg}+7$ & $\mathrm{R}$ & & & $\mathrm{Pg}+7$ & Blastocyst & - & \\
\hline P15 & $\mathrm{Pg}+6$ & NR & $\mathrm{Pg}+8$ & $\mathrm{R}$ & $\mathrm{Pg}+8$ & Blastocyst & + & + \\
\hline P16 & $\mathrm{Pg}+7$ & $\mathrm{R}$ & & & $\mathrm{Pg}+7$ & Blastocyst & - & \\
\hline P17 & $\mathrm{Pg}+6$ & PR & & & $\mathrm{Pg}+8$ & Blastocyst & - & \\
\hline P18 & $\mathrm{Pg}+8$ & $\mathrm{R}$ & & & $\mathrm{Pg}+6$ & 2 day 3 embryos & + & $+(1 \mathrm{sac})$ \\
\hline P19 & $\mathrm{Pg}+5.5$ & PR & & & $\mathrm{Pg}+7.5$ & Blastocyst & + & + \\
\hline $\mathrm{P} 20$ & $\mathrm{Pg}+5.5$ & PR & & & $\mathrm{Pg}+5.5$ & 2 day 3 embryos & + & $+(2 \mathrm{sacs})$ \\
\hline
\end{tabular}

Table 4: Results of the Win-Test in each patient with repeated implantation failures. PR, partially receptive; NR, non-receptive; $R$, receptive.

\section{3-Discussion}

This study shows that the global gene expression profile of endometrial samples from HRT-treated OD recipients six day after the beginning of progesterone administration is different from the control group. Using the Win test $^{\circledR}$ for endometrial receptivity assessment, we did note that the majority of peri-implantation receptive endometrium samples from HRT-treated patients, from both OD recipient patients with or without RIF, presents an inadequate endometrial status after 5/6 days of progesterone treatment with either a 'partially' or 'non-receptive' profile.

Global endometrial gene expression profile during the peri-implantation phase in HRT cycles In the present study, we analysed the whole the gene expression profiles of pre-receptive endometrial transcriptome at $\mathrm{Pg}+5$ in OD recipient patients under HRT cycle. Using this global approach, we identified significant changes (mainly over-expression) in ECM and adhesion-related genes, including several integrins (ITGAL, ITFGl, ITGBIBPl) and collagens (COLAA1, COL1A2, COLAA3BP), in the endometrium of HRT-supplemented OD recipients. However, none of the ECM and adhesion-related genes identified by Zhao et al. (2010) as significantly deregulated during the implantation window in IVF cycles with luteal support was found in the present the study design. Nevertheless, none of the genes identified by Zhao et al. (2010) was previously reported as potential biomarker of endometrial receptivity in studies comparing study. This can be explained by differences in 
and receptive secretory phase endometrium in natural cycles (Haouzi et al., 2012), reinforcing the notion that these genes are specifically deregulated by HRT. We also found that several growth factors, including members of the vascular endothelial growth factor (VEGF) system, were altered in patients receiving HRT. Both VEGFB and its receptor

VEGFR1 were down-regulated during the peri-implantation period in OD recipient patients under HRT. These genes were previously reported as over-expressed during the implantation window in spontaneous cycles compared to the pre-receptive secretory stage (Carson et al., 2002; Meduri et al., 2000). VEGF is an angiogenic factor with a primary role in blood vessel development in uterine endometrium during embryo implantation and is essential for decidual vascularization (Sidell et al., 2010; Wu et al., 2011). The CD44 gene was also downregulated in HRT-treated oocyte-donation recipients. This gene was previously reported as over-expressed during the implantation window in spontaneous cycles (Mirkin et al., 2005; Talbi et al., 2006; Haouzi et al., 2009, 2011). CD44 is a hyaluronic acid receptor and might play a role in blastocyst attachment by interacting with sulphated proteoglycans expressed by early human embryos (Afify et al., 2006). Dysregulation of these processes can result in defective implantation. Indeed, individual analysis of the microarray data indicated that the expression level of these two genes was lower in OD-donation recipients who did not get pregnant than in those who did get.

Compared to control group, oestrogen receptor signalling was also altered during the peri-implantation period in recipient patients (most genes related to this pathway were upregulated). Oestrogens and progesterone act via nuclear receptors that function as ligandactivated transcription factors and chromatin modifiers to directly regulate the expression of many genes. Other oestradiol-responsive genes are also regulated by oestrogen receptor via protein-protein interactions. These effects are mediated through co-regulators associated with a multi-subunit DNA-binding complex that includes RNA polymerase II. POLR2E was down-regulated in endometrial samples from recipient patients receiving HRT compared to control group, while

POLR2B was up-regulated. In addition, several genes encoding subunits of the mediator complex (MED), a transcriptional co-activator complex thought to be required for the expression of almost all genes, were up-regulated (MED13, MED17 and MED31) in endometrium from HRT-treated recipient patients, but not MED16 which was downregulated. These data strongly suggest a still too strong estrogenic action during the luteal 
phase of oestradiol/progesteronesupplemented cycles compared to control group. It is well known that endometrial maturation for embryo implantation must be achieved by the time of progesterone exposure, and thus, only after sufficient and adequate exposure to oestrogen. However, the identification of the optimal dose of steroids remains a challenge as several recent studies demonstrated that (i) serum oestradiol levels do not reflect the corresponding endometrial tissue concentration, and (ii) local effects of steroids can be strongly influenced by the local metabolism (Marchais-Oberwinkler et al., 2011; Huhtinen et al., 2012). More precisely, oestrogen concentration in endometrium can be controlled by oestrogenmetabolizing enzymes and specifically by hydroxysteroid dehydrogenase (HSD17B) that regulates the balance between oestradiol and oestrone. In healthy women, the intra-tissue oestradiol concentration is actively reduced in the endometrial secretory phase (compared with the proliferative phase) and is about half of the serum concentration. Here, we found over-expression of HSDL2, the gene encoding hydroxysteroid dehydrogenase-like protein 2 . Using the Biograph data mining/integration platform, putative functional relations were found between HSDL2 and oestradiol with intermediate links involving retinol dehydrogenases (RDHs) and dehydrogenases/reductases (DHRSs) (Liekens et al., 2011). RDH5, DHRS3 and DHRSX were up-regulated in the peri-implantation endometrium of HRT-treated OD recipients compared to patients in spontaneous cycles. However, their altered expression does not seem to affect the pregnancy outcome, because we did not detect any significant difference in their expression profile by microarray analysis in endometrial samples from pregnant and non-pregnant patients in the OD recipient group. In addition, comparison of the global endometrial gene expression profiles according to the pregnancy outcome (pregnant versus nonpregnant) did not highlight any gene-related variables affecting the outcome.

\section{Personalized embryo transfers (PET) according to the Win-Test ${ }^{\circledR}$ results}

Based on the molecular analysis of endometrial biopsies during the periimplantation period at $\mathrm{Pg}+5 /+6$, our findings strongly suggest a 'non-optimal receptivity' in most HRT-treated patients. Other studies have previously suggested a lag in endometrial development in artificially prepared cycles and/or non-synchronization between glandular and stromal development (Bourgain et al., 1990; Younis et al., 1991; Nikas et al., 1995; Zenke and Chetkowski, 2004; Ruiz-Alonso et al., 2014). It is not clear to which extent a small lag in endometrial development can affect endometrial receptivity, and subsequently pregnancy outcome. On the $16 \mid \mathrm{P}$ a g e 
other hand, no pregnancy was observed when histologically advanced endometrial maturation exceeded three days (Van Vaerenbergh et al., 2009).

Using previously described biomarkers of endometrial receptivity (Win-Test $\left.{ }^{\circledR}\right)$, we found that $71 \%$ of endometrium samples taken from OD recipients at $\mathrm{Pg}+5$ during HRT were only partially receptive. We did not find any significant difference in the expression of these endometrial receptivity biomarkers relative to the patients' characteristics (age, $\mathrm{BMI})$, clinical features, endometrial aspect or other Doppler parameters between recipient patients. This is in agreement with previous studies showing that neither endometrial thickness nor Doppler pattern could predict the optimal receptivity and, therefore, the outcome in OD recipients (Check et al., 1993; Zenke and Chetkowski, 2004).

In OD RIF patients, $86 \%$ of endometrium samples at $\mathrm{Pg}+5 /+6$ were classified as either 'partially' (43\%) or 'non-receptive' (43\%) by the Win-Test ${ }^{\circledR}$; while at $\mathrm{Pg}+7 /+8$, majority were diagnosed as 'receptive' (77\%). This response heterogeneity observed at $\mathrm{Pg}+5 /+6$ treatment timing is independent of the progesterone dose administrated and it seems that treatment duration is an essential factor for complete endometrial maturation. At this specific HRT-cycle timing $(\mathrm{Pg}+5 /+6)$, majority of ART centres perform blastocyst replacement (Nawroth and Ludwig, 2005; Shapiro et al., 2014). However, our results suggest that endometrium under HRT regimen is receptive not before at least seven days of progesterone treatment. In which measure this maturation delay is due to the patient's characteristics (OD RIF patients) or the reflection of the optimal timing for endometrial preparation under HRT remains a full question. On the other hand, endometria from HRT-treated OD recipients evaluated at $\mathrm{Pg}+5$ were also mainly 'partially receptive', suggesting an incomplete endometrial maturation at this treatment timing. In view of this finding, we can't exclude the possibility that the difference in the global gene expression profile of endometrial samples from HRT-treated oocyte-donation recipients at $\mathrm{Pg}+5$ and control group at $\mathrm{LH}+7$ was not the reflection of this endometrial maturity difference.

This finding underlines the need to take into account the individual patient response to artificial cycles. To this aim, the assessment of endometrial receptivity biomarkers, an easy method applicable in routine ART programmes, can help (i) determining the optimal individual response to HRT, and therefore, (ii) identifying the best embryo transfer timing during artificial supplemented cycles. These considerations, while respecting the synchronization of embryo-endometrium dialogue, could optimize pregnancy rates: 
day-2/3 embryos replacement when endometrium is partially receptive and blastocyst stage when endometrium is receptive. Although

levels are still preliminary, the strategy replacement according to the Win-Test $^{\circledR}$ seems promising with $50 \%$ of pregnancy rate per frozen-thawed embryo replacement in OD RIF patients. The present study demonstrates that majority of HRT-treated patients have a partially receptive endometrium after five/six days of progesterone treatment. This remains compatible with embryos replacement on day2/3 developmental stage. In OD RIF Patients, a more response heterogeneousness to the progesterone treatment, at this same HRTcycle timing, was observed, underlining the necessity to evaluate the endometrial status at this specific timing, to target a personalized patient care management for embryo transfers.

\section{Acknowledgements}

We thank the ART teams for their assistance during this study. We would like to pay our respects to Dr. Paul Cohen-Bacri, who passed away during this study. He was in charge of the ART department of Eylau-Unilabs and participated actively in the present study. This article is dedicated to him.

\section{Funding}

This work was partially supported by a grant from the Ferring Pharmaceuticals and GFI Copyright 2015 KEI Journals. All Rights Reserved
Merck Serono companies, and FEDER (Fonds européen de développement régional).

\section{References}

Afify AM, Craig S, Paulino AF. Temporal variation in the distribution of hyaluronic acid,CD44s, and CD44v6 in the human endometrium across the menstrual cycle. Appl Immunohistochem Mol Morphol. 2006;14(3):328-333.

Bourgain C, Devroey P, Van Waesberghe L, Smitz J, Van Steirteghem AC. Effects of natural progesterone on the morphology of the endometrium in patients with primary ovarian failure. Hum Reprod. 1990;5(5):537543.

Ceyhan ST, Basaran M, Kemal Duru N, Yilmaz A, Göktolga U, Baser I. Use of luteal estrogen supplementation in normal responder patients treated with fixed multidose $\mathrm{GnRH}$ antagonist: a prospective randomized controlled study. Fertil Steril. 2008;89(6):1827-1830.

Check JH, Nowroozi K, Choe J, Lurie D, Dietterich C. The effect of endometrial thickness and echo pattern on in vitro fertilization outcome in donor oocyte-embryo transfer cycle. Fertil Steril. 1993;59(1):72-75.

De Hoon MJ, Imoto S, Nolan J, Miyano S. Open source clustering software. $18 \mid \mathrm{P}$ a g e 
Bioinformatics 2004;20:1453-1454.

Díaz-Gimeno P, Horcajadas JA, MartínezConejero JA, Esteban FJ, Alamá P, Pellicer A, Simón C. A genomic diagnostic tool for human endometrial receptivity based on the transcriptomic signature. Fertil Steril. 2011;95(1):50-60, 60.e1-15.

Engmann L, DiLuigi A, Schmidt D, Benadiva C, Maier D, Nulsen J. The effect of luteal phase vaginal estradiol supplementation on the success of in vitro fertilization treatment: a prospective randomized study. Fertil Steril. 2008;89(3):554-561.

Farhi J, Weissman A, Steinfeld Z, Shorer M, Nahum H, Levran D. Estradiol supplementation during the luteal phase may improve the pregnancy rate in patients undergoing in vitro fertilization-embryo transfer cycles. Fertil Steril. 2000;73(4):761766.

Fatemi HM, Kolibianakis EM, Camus M, Tournaye H, Donoso P, Papanikolaou E Devroey P. Addition of estradiol to progesterone for luteal supplementation in patients stimulated with $\mathrm{GnRH}$ antagonist/rFSH for IVF: a randomized controlled trial. Hum Reprod. 2006;21(10):2628-2632.

Garcia-Velasco JA, Motta L, López A, progesterone elevation on the day of HCG Mayoral M, Cerrillo M, Pacheco A. Low-dose administration. Biomed Res Int. human chorionic gonadotropin versus estradiol/progesterone luteal phase support in gonadotropin-releasing hormone agonisttriggered assisted reproductive technique cycles: understanding a new approach. Fertil Steril. 2010;94(7):2820-2823.

Gleicher N, Brown T, Dudkiewicz A, Karande V, Rao R, Balin M, Campbell D, Pratt D. Estradiol/progesterone substitution in the luteal phase improves pregnancy rates in stimulated cycles-but only in younger women. Early Pregnancy 2000;4:64-73.

Glujovsky D, Pesce R, Fiszbajn G, Sueldo C, Hart RJ, Ciapponi A. Endometrial preparation for women undergoing embryo transfer with frozen embryos or embryos derived from donor oocytes. Cochrane Database Syst Rev. 2010;(1):CD006359.

Gorkemli H, Ak D, Akyurek C, Aktan M, Duman S. Comparison of pregnancy outcomes of progesterone or progesterone + estradiol for luteal phase support in ICSI-ET cycles. Gynecol Obstet Invest. 2004;58(3):140-144.

Haouzi D, Bissonnette L, Gala A, Assou S, Entezami F, Perrochia H, Dechaud H, Hugues JN, Hamamah S. Endometrial receptivity profile in patients with premature 
2014;2014:951937.

Kolibianakis EM, Venetis CA, Papanikolaou Haouzi D, Dechaud H, Assou S, De Vos J, EG, Diedrich K, Tarlatzis BC, Griesinger G. Hamamah S. Insights into human endometrial Estrogen addition to progesterone for luteal receptivity from transcriptomic and proteomic phase support in cycles stimulated with GnRH data. Reprod Biomed Online. 2012;24(1):2334.

analogues and gonadotrophins for IVF: a systematic review and meta-analysis. Hum Reprod. 2008;23(6):1346-1354.

Haouzi D, Dechaud H, Assou S, Monzo C, de Vos J, Hamamah S. Transcriptome analysis reveals dialogues between human trophectoderm and endometrial cells during the implantation period. Hum Reprod. 2011;26(6):1440-1449.

Haouzi D, Mahmoud K, Fourar M, Bendhaou

Lewin A, Benshushan A, Mezker E, Yanai N, Schenker JG, Goshen R. The role of estrogen support during the luteal phase of in vitro fertilization-embryo transplant cycles: a comparative study between progesterone alone and estrogen and progesterone support. Fertil Steril 1994;62:121-125.

K, Dechaud H, De Vos J, Rème T, Dewailly D, Hamamah S. Identification of new biomarkers of human endometrial receptivity in the natural cycle. Hum Reprod. 2009;24(1):198-205.

Liekens AM, De Knijf J, Daelemans W, Goethals B, De Rijk P, Del-Favero J. BioGraph: unsupervised biomedical knowledge discovery via automated hypothesis generation. Genome Biol.

Huhtinen K, Desai R, Ståhle M, Salminen A, 2011;12(6):R57.

Handelsman DJ, Perheentupa A, Poutanen M. Endometrial and endometriotic concentrations of estrone and estradiol are determined by local metabolism rather than circulating levels. J Clin Endocrinol Metab. 2012;97(11):4228-4235.

Lukaszuk K, Liss J, Lukaszuk M, Maj B. Optimization of estradiol supplementation during the luteal phase improves the pregnancy rate in women undergoing in vitro fertilization-embryo transfer cycles. Fertil Jung H, Roh HK. The effects of E2 Steril. 2005;83(5):1372-1376.

supplementation from the early proliferative phase to the late secretory phase of the Marchais-Oberwinkler S, Henn C, Möller G, endometrium in hMGstimulated IVF-ET. J Klein T, Negri M, Oster A, Spadaro A, Werth Assist Reprod Genet 2000;17:28-33.

R, Wetzel M, Xu K et al. 17ß-Hydroxysteroid 
dehydrogenases (17 $\beta$-HSDs) as therapeutic targets: protein structures, functions, and recent progress in inhibitor development. $\mathbf{J}$ Steroid Biochem Mol Biol. 2011;125(1-2):6682.

Meduri G, Bausero P, Perrot-Applanat M. Expression of vascular endothelial growth factor receptors in the human endometrium: modulation during the menstrual cycle. Biol Reprod. 2000;62(2):439-47.

Mirkin S, Arslan M, Churikov D, Corica A, Diaz JI, Williams S, Bocca S, Oehninger S. In search of candidate genes critically expressed in the endometrium during the window of implantation. Hum Reprod 2005;20:21041217.

Nawroth F, Ludwig M. What is the 'ideal' duration of progesterone supplementation before the transfer of cryopreserved-thawed embryos in estrogen/progesterone replacement protocols? Hum Reprod. 2005;20(5):1127-34.

Nikas G, Drakakis P, Loutradis D, MaraSkoufari C, Koumantakis E, Michalas S, Psychoyos A. Uterine pinopodes as markers of the 'nidation window' in cycling women receiving exogenous oestradiol and progesterone. Hum Reprod. 1995;10(5):12081213.
Ruiz-Alonso M, Blesa D, Díaz-Gimeno P, Gómez E, Fernández-Sánchez M, Carranza F, Carrera J, Vilella F, Pellicer A, Simón C. The endometrial receptivity array for diagnosis and personalized embryo transfer as a treatment for patients with repeated implantation failure. Fertil Steril. 2013;100(3):818-824.

Ruiz-Alonso M, Galindo N, Pellicer A, Simón C. What a difference two days make: "personalized" embryo transfer (pET) paradigm: A case report and pilot study. Hum Reprod. 2014;29(6):1244-1247.

Serna J, Cholquevilque JL, Cela V, MartínezSalazar J, Requena A, Garcia-Velasco JA. Estradiol supplementation during the luteal phase of IVF-ICSI patients: a randomized, controlled trial. Fertil Steril. 2008;90(6):21902195.

Shapiro DB, Pappadakis JA, Ellsworth NM, Hait HI, Nagy ZP.Progesterone replacement with vaginal gel versus i.m. injection: cycle and pregnancy outcomes in IVF patients receiving vitrified blastocysts. Hum Reprod. 2014;29(8):1706-11.

Sidell N, Feng Y, Hao L, Wu J, Yu J, Kane MA, Napoli JL, Taylor RN. Retinoic acid is a cofactor for translational regulation of vascular endothelial growth factor in human endometrial stromal cells. Mol Endocrinol. 2010;24(1):148-160. 
Smitz J, Bourgain C, Van Waesberghe L, stimulated cycles, advanced endometrial Camus M, Devroey P, Van Steirteghem AC. maturation on the day of oocyte retrieval A prospective randomized study on oestradiol valerate supplementation in addition to correlates with altered gene expression. Hum Reprod. 2009;24(5):1085-1091.

intravaginal micronized progesterone in buserelin and HMG induced superovulation. Hum Reprod 1993;8:40-45.

Talbi S, Hamilton AE, Vo KC, Tulac S, Overgaard MT, Dosiou C, Le Shay N, Nezhat CN, Kempson R, Lessey BA et al. Molecular phenotyping of human endometrium distinguishes menstrual cycle phases and underlying biological processes in normoovulatory women. Endocrinology 2006;147:1097-1121.

Tusher VG, Tibshirani R, Chu G. Significance analysis of microarrays applied to the ionizing radiation response. Proc Natl Acad Sci USA 2001; 98:5116-5121.
Wu J, Hansen JM, Hao L, Taylor RN, Sidell N. Retinoic acid stimulation of VEGF secretion from human endometrial stromal cells is mediated by production of reactive oxygen species. J Physiol. 2011;589(Pt 4):863-875.

Younis JS, Mordel N, Ligovetzky G, Lewin A, Schenker JG, Laufer N. The effect of a prolonged artificial follicular phase on endometrial development in an oocyte donation program. J In Vitro Fert Embryo Transf. 1991;8(2):84-88.

Zenke U, Chetkowski RJ. Transfer and uterine factors are the major recipient-related determinants of success with donor eggs. Fertil Steril. 2004;82(4):850-856.

van der Linden M, Buckingham K, Farquhar C, Kremer JA, Metwally M. Luteal phase support for assisted reproduction cycles. Cochrane Database Syst Rev. 2011;(10):CD009154.

Van Vaerenbergh I, Van Lommel L, Ghislain V, In't Veld P, Schuit F, Fatemi HM, Devroey $\mathrm{P}$, Bourgain C. In GnRH antagonist/rec-FSH

Zhao Y, Garcia J, Kolp L, Cheadle C, Rodriguez A, Vlahos NF. The impact of luteal phase support on gene expression of extracellular matrix protein and adhesion molecules in the human endometrium during the window of implantation following controlled ovarian stimulation with a GnRH antagonist protocol. Fertil Steril. 2010;94(6):2264-2271. 


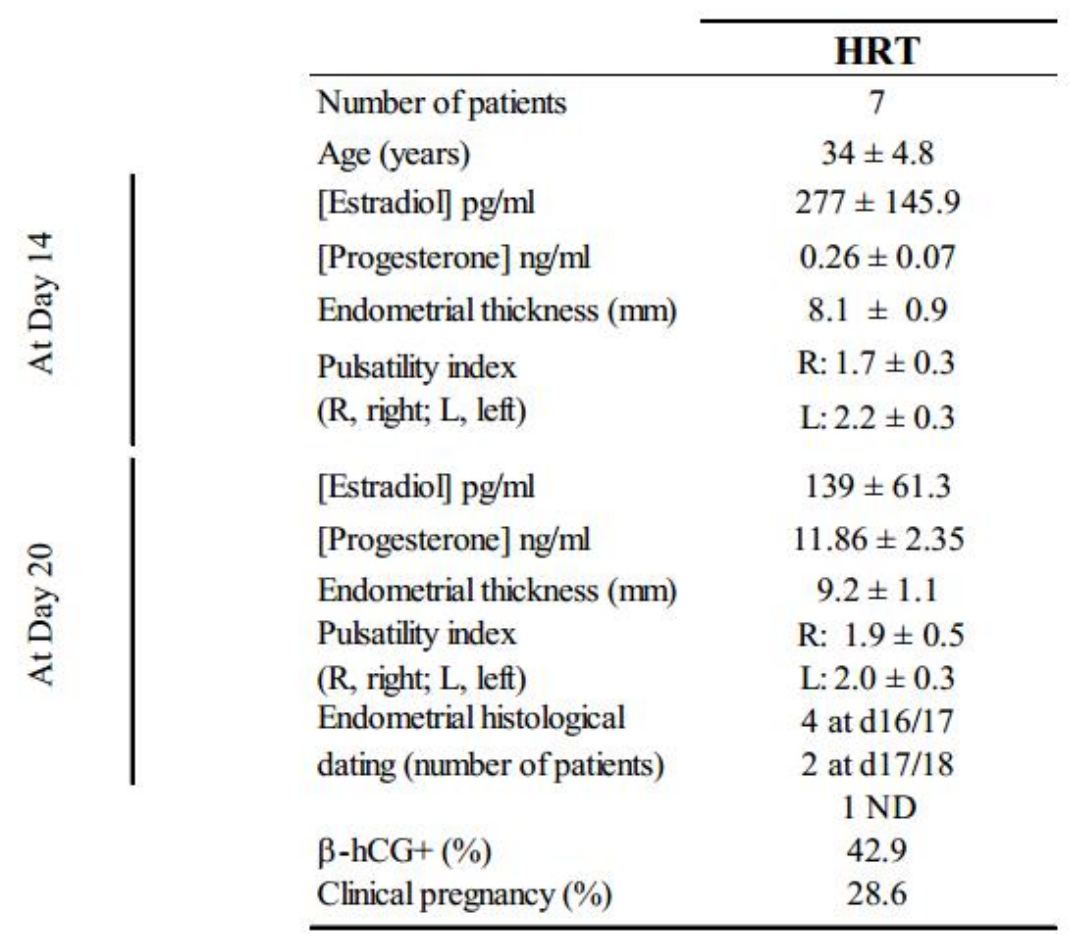

Supplementary Table 1: Clinical characteristics and pregnancy outcome in oocyte-donation recipients.

$\mathrm{ND}$, not determined. 

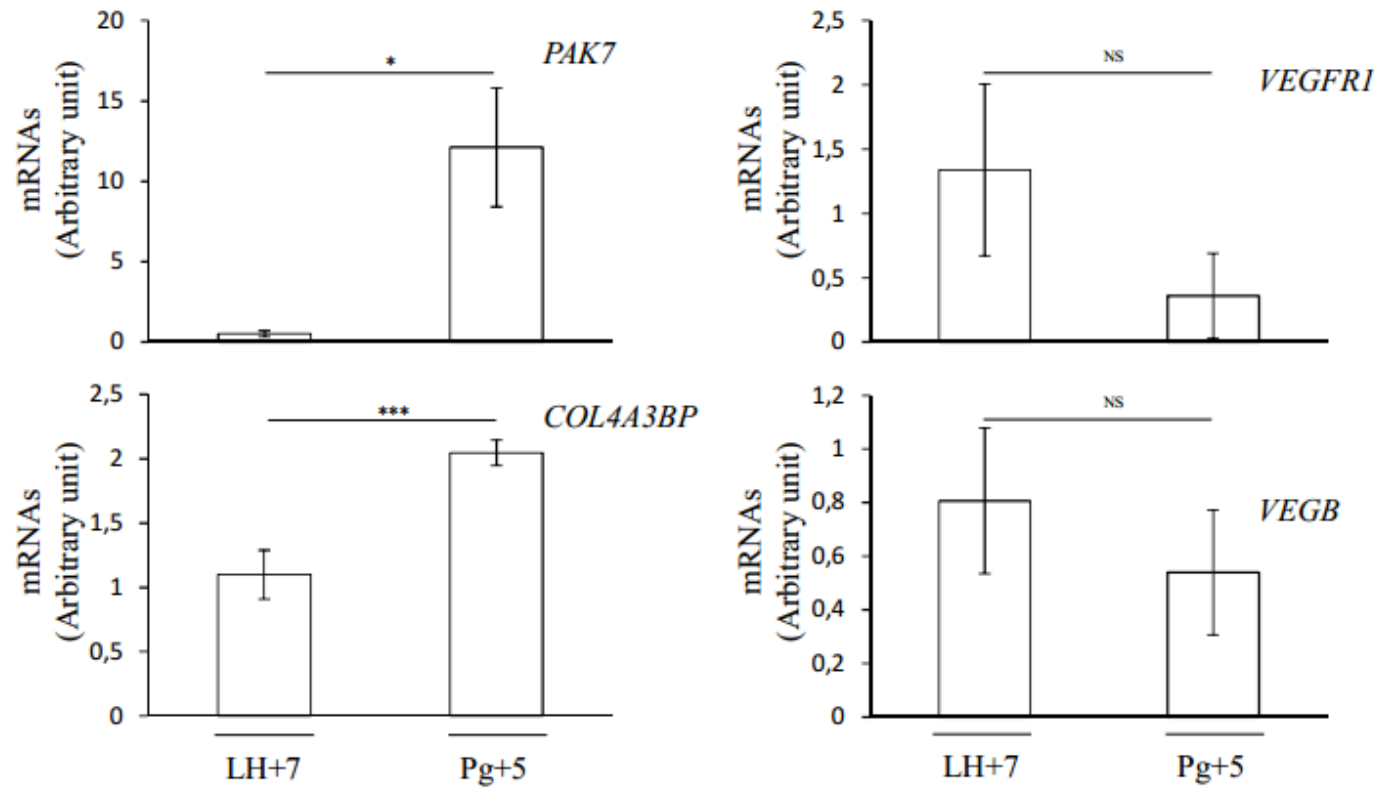

Supplementary Figure 1: Validation by RT-qPCR of some genes encoding factors related to the signalling pathways the expression of which is altered in the endometrium of HRT-treated oocyte-donation recipients $(\mathrm{Pg}+5)$ compared to patients in spontaneous cycle $(\mathrm{LH}+7$ samples $)$. Data are the mean \pm SEM. ${ }^{* * *}, \mathrm{p}<0.001 ; *, \mathrm{p}<0.05 ; \mathrm{NS}$, non-significant. 